\title{
Immune modulation and increased neurotrophic factor production in multiple sclerosis patients treated with testosterone Stefan M Gold ${ }^{1,2}$, Sara Chalifoux ${ }^{1}$, Barbara S Giesser ${ }^{1}$ and Rhonda R Voskuhl*1
}

Address: ${ }^{1}$ Department of Neurology, Neuroscience Research Building 1, 635 Charles E. Young Drive South, University of California Los Angeles, CA, 90095, USA and 2Cousins Center, 300 Medical Plaza, University of California Los Angeles, CA, 90095, USA

Email: Stefan M Gold - sgold@mednet.ucla.edu; Sara Chalifoux - sarachalifoux@ucla.edu; Barbara S Giesser - bgiesser@mednet.ucla.edu; Rhonda R Voskuhl* - rvoskuhl@ucla.edu

* Corresponding author

Published: 31 July 2008

Journal of Neuroinflammation 2008, 5:32 doi:10.1 186/1742-2094-5-32
Received: 29 May 2008

Accepted: 31 July 2008

This article is available from: http://www.jneuroinflammation.com/content/5/I/32

(c) 2008 Gold et al; licensee BioMed Central Ltd.

This is an Open Access article distributed under the terms of the Creative Commons Attribution License (http://creativecommons.org/licenses/by/2.0),

which permits unrestricted use, distribution, and reproduction in any medium, provided the original work is properly cited.

\begin{abstract}
Background: Multiple sclerosis is a chronic inflammatory disease of the central nervous system with a pronounced neurodegenerative component. It has been suggested that novel treatment options are needed that target both aspects of the disease. Evidence from basic and clinical studies suggests that testosterone has an immunomodulatory as well as a potential neuroprotective effect that could be beneficial in MS.

Methods: Ten male MS patients were treated with $10 \mathrm{~g}$ of gel containing $100 \mathrm{mg}$ of testosterone in a cross-over design ( 6 month observation period followed by 12 months of treatment). Blood samples were obtained at three-month intervals during the observation and the treatment period. Isolated blood peripheral mononuclear cells (PBMCs) were used to examine lymphocyte subpopulation composition by flow cytometry and ex vivo protein production of cytokines (IL-2, IFN $\gamma$, TNF $\alpha$, IL- I7, IL- I0, IL- I 2p40, TGF $\beta$ I) and growth factors (brain-derived neurotrophic factor BDNF, platelet-derived growth factor PDGF-BB, nerve growth factor NGF, and ciliary neurotrophic factor CNTF). Delayed type hypersensitivity (DTH) skin recall tests were obtained before and during treatment as an in vivo functional immune measure.

Results: Testosterone treatment significantly reduced DTH recall responses and induced a shift in peripheral lymphocyte composition by decreasing CD4+ T cell percentage and increasing NK cells. In addition, PBMC production of IL- 2 was significantly decreased while TGF $\beta$ I production was increased. Furthermore, PBMCs obtained during the treatment period produced significantly more BDNF and PDGF-BB.

Conclusion: These results are consistent with an immunomodulatory effect of testosterone treatment in MS. In addition, increased production of BDNF and PDGF-BB suggests a potential neuroprotective effect.
\end{abstract}

Trial Registration: NCT00405353 http://www.clinicaltrials.gov 


\section{Background}

Multiple sclerosis (MS) has been considered a putative T cell mediated autoimmune disease. However, it is becoming increasingly clear that its pathology is far more complicated and is characterized by both an inflammatory component as well as a neurodegenerative process [1]. To date, the relationship between inflammation and the neurodegeneration in MS is unclear. Nevertheless, it is currently thought that potential new treatments should ideally have anti-inflammatory as well as neuroprotective properties [2].

Numerous models of autoimmune diseases including experimental autoimmune encephalomyelitis (EAE), diabetes in nonobese mice, thyroiditis, and adjuvant arthritis have been shown to be worsened by castration of male animals [3-8]. Furthermore, testosterone treatment ameliorates EAE [9]. These protective effects are thought to be mediated by testosterone's immunomodulatory properties such as decreasing the production of pro-inflammatory cytokines TNF $\alpha$ and IL-1 $\beta$ by macrophages $[10]$ and monocytes [11] as well as increasing production of the anti-inflammatory cytokine IL-10 by T cells [12].

In addition, evidence supporting a neuroprotective effect of testosterone has been found in a variety of neurological diseases as well as in the cognitive decline associated with normal aging [13]. Testosterone is converted to estrogen in the brain by aromatase, and the neuroprotective properties of testosterone treatment in vivo may be due at least in part to this conversion. However, several in vitro studies have shown that testosterone can also be more directly neuroprotective [14]. Testosterone has been shown to protect spinal cord neurons in culture from glutamatemediated toxicity, as well as to induce neuronal differentiation and increase neurite outgrowth [15]. Testosterone treatment also protected cultured neurons against betaamyloid toxicity induced cell death [16].

While CNS infiltrating immune cells were once thought to always be deleterious, it has since been established that they have the potential to be beneficial under certain conditions, since neurotrophic factors have been detected in peripheral blood mononuclear cells (PBMCs) [17]. Indeed, production of the neurotrophic factors BDNF and NT-3 by immune cells has been shown to accompany better recovery from spinal cord injury [18], and the production of neurotrophic factors by immune cells has been hypothesized as a potential means of neuroprotection in MS [19].

Recently, a pilot clinical trial using testosterone to treat 10 male MS patients was completed [20]. In these patients, cognitive function improved and the brain atrophy rate was significantly slowed. Here, immunomodulatory effects of testosterone treatment as well as its ability to induce neurotrophic growth factor production in PBMCs were examined in these patients to explore a potential novel pathway underlying testosterone's beneficial effects.

\section{Methods Subjects}

Ten men (mean age 46, range 29-61) who met Poser criteria for clinically definite relapsing-remitting (RR) MS, were not currently receiving disease modifying treatment and had a mean Expanded Disability Status Score (EDSS) of 2.0 (range 1.5-2.5) were studied. A six month pretreatment observation period (month -6 to 0 ) was followed by twelve months (months 1 to 12 ) of treatment with $10 \mathrm{~g}$ of gel containing $100 \mathrm{mg}$ of testosterone $\left(\right.$ AndroGel ${ }^{\circledR}$ ) applied to the upper arms once per day. Treatment increased circulating testosterone levels from the lower normal range to the higher range of normal, with average increases of $50 \%$ [20].

Every three months clinical examinations were done and blood was drawn to collect PBMCs. The protocol was approved by the UCLA Human Subjects Protection Committee and all patients provided written informed consent prior to enrollment in the study.

\section{Delayed type hypersensitivity (DTH) test}

Delayed type hypersensitivity (DTH) recall responses to tetanus (Tetanus Toxoid; Wyeth Laboratories, Marietta, PA) were assessed at two time points: once in the pretreatment period at study month 0 and once in the middle of the treatment period at study month 6 , as described [21].

\section{PBMC phenotyping and ex vivo stimulation}

Cryopreserved PBMCs collected every three months throughout the pretreatment and treatment periods were thawed and analyzed simultaneously for every patient. PBMC subpopulations before (month 0 ) and at the end of treatment (month 12) were determined by flow cytometry. One aliquot of cells was stained for cell surface markers with a panel of conjugated Abs, including CD3 (FITC), CD64 (FITC), CD14 (PE), CD4 (PE), CD8 (PE), CD16+56 (PE), CD45 (PerCP) and CD19 (Per-CP) (BD Bioscience) to determine subpopulations.

For ex vivo protein production, PBMCs were cultured at 1 $\times 10^{5}$ cells/well with either $(1)$ anti-CD3 $(1 \mu \mathrm{g} / \mathrm{ml}$; SigmaAldrich, St. Louis, MO) and anti-CD28 $(2.5 \mu \mathrm{g} / \mathrm{ml}$; SigmaAldrich), or (2) PHA (5 $\mu \mathrm{g} / \mathrm{ml}$; Sigma-Aldrich) or (3) media alone, as described [22] Protein levels were assayed in supernatants at $48 \mathrm{~h}$ and $72 \mathrm{~h}$ using SearchLight multiplex assays for growth factors (brain-derived neurotrophic factor BDNF, platelet-derived growth factor PDGF-BB, nerve growth factor NGF, and ciliary neurotrophic factor 
CNTF) and cytokines (IL-2, IFN $\gamma, \mathrm{TNF} \alpha$, IL-17, IL-10, IL12p40, TGF $\beta 1$ ).

\section{Primary neuronal cultures}

Primary CNS cell cultures were prepared from P0 C57BL/ 6 pups. Forebrain tissue was removed, dissociated, and plated on poly-D-lysine coated $18 \mathrm{~mm}$ coverslips in 12 well culture plates. Dissociated brain tissue from littermates was pooled and plated at a density of $10,000 \mathrm{cell} / \mathrm{ml}$ in Neurobasal media (Gibco) containing 2\% B27 supplement (Invitrogen), 1\% Penicillin-Streptomycin, $0.5 \mathrm{mM}$ L-glutamine, and $10 \mathrm{ng} / \mathrm{ml}$ NGF (Invitrogen). All experiments were done with the approval of the UCLA Committee for the Protection of Research Subjects. Cells were cultured for 10 days with media exchanged every three days. Then, cells were washed $2 \times$ in RPMI and exposed to $1 \mathrm{mM}$ glutamate for $2 \mathrm{~h}$ in the presence or absence of growth factors to test the biological significance of the combination and dose of growth factors produced by immune cells. Brightfield microscopy images of TUNEL (Roche) stained culture slides were obtained at $40 \times$ to visualize neurons. Lactate Dehydrogenase (LDH) is a stable cytoplasmatic enzyme present in all cells, which is rapidly released into the cell culture upon damage of the plasma membrane and its quantification can be used as an objective measure of cell damage. LDH levels were measured with a commercially available Cytotoxicity Detection Kit (Roche) according to manufacturer's instructions at 490 $\mathrm{nm}$ on a Multiskan plate reader.

\section{Statistical analysis}

For growth factor and cytokine levels, the two baseline values (month -3 and month 0 ) were averaged and all values were log-transformed to achieve a normal distribution. Changes in growth factor and cytokine levels were tested using repeated measures ANOVA including all stimulation conditions and incubation times. In case of a significant main effect for time in the ANOVA, exploratory pairwise comparisons were computed to determine significant increases over baseline. Changes in lymphocyte subpopulations, DTH recall test results and in vitro neurotoxicity results were compared using paired t tests. Pearson correlation coefficients were computed to examine the association between changes in production of cytokines and growth factors from baseline to 12-month of treatment and changes in DTH and clinical outcomes. A value of $\mathrm{p}<.05$ was considered significant.

\section{Results}

Testosterone treatment significantly decreased CD4 T cell populations (average decrease $17 \%, \mathrm{p}=.03$ ) while increasing NK cell populations (average increase 64\%, $\mathrm{p}=$ .03 , Figure 1A). Furthermore, DTH recall responses were significantly decreased during treatment compared to pre- treatment values (mean millimeters induration pre-treatment $11.2 \pm 2.3$; treatment $6.5 \pm 1.8, \mathrm{p}=.03$, Figure $1 \mathrm{~B}$ )

Regarding effects of testosterone treatment on cytokine levels, there was a significant decrease in IL-2 production during the treatment period as compared to pretreatment baseline $(\mathrm{p}<.001$, Figure 1C). Average decreases in IL-2 were $-34 \%$ for CD3/CD28 and $-58 \%$ for PHA stimulation. In contrast, a significant increase was observed in TGF $\beta 1$ levels ( $\mathrm{p}<.0001$, Figure 1D) with average increases of $167 \%$ for CD3/CD28 and 179\% over baseline for PHA stimulations. No significant changes were observed in other cytokines (IFN $\gamma, \mathrm{TNF} \alpha$, IL-10, IL-17, IL-12p40) tested.

Testosterone treatment significantly increased levels of growth factors in supernatants of ex vivo stimulated PBMCs. Specifically, BDNF levels in PBMC supernatants revealed average increases of over 9 fold at treatment month 12 , as compared to pretreatment baseline, for CD3/CD28 stimulation, and almost 11 fold for PHA stimulation, $(\mathrm{p}<.0001$, Figure 1E). Highly significant increases in PDGF-BB production were also observed during testosterone treatment, with PDGF-BB levels increasing approximately 3.5 fold during both $\mathrm{CD} 3 / \mathrm{CD} 28$ and PHA stimulation conditions $(\mathrm{p}<.0001$, Figure $1 \mathrm{~F})$. No significant changes were observed in other growth factors (NGF, CNTF) tested.

Correlation coefficients of cytokine and growth factor changes with functional and clinical outcomes were computed as an exploratory analysis. The increases in BDNF, PDGF-BB and TGF $\beta 1$ production were significantly correlated (TGF $\beta 1$ and BDNF $\mathrm{r}=.72$; TGF $\beta 1$ and PDGF-BB, $\mathrm{r}=$ .89; BDNF and PDGF-BB, $\mathrm{r}=.91$ ). There was a moderate (but not significant) correlation between TGF $\beta 1$ and IL-2 changes $(r=.48)$. Interestingly, there was a positive association between the decrease in CD4+ cells and decreased responses in the DTH skin test $(r=.59)$ that showed a statistical trend $(\mathrm{p}=.07)$. However, changes in IL-2 did not significantly correlate with either CD4+ percentage or DTH. As reported previously [20], testosterone treatment in our study increased cognitive function as measured by the Paced Auditory Serial Addition Task (PASAT). Percent increases in BDNF $(\mathrm{r}=.74, \mathrm{p}=.01)$ and PDGF-BB $(\mathrm{r}=.73$, $\mathrm{p}=.02$ ) from baseline to month 12 of treatment were significantly associated with improvements in PASAT testing during the same time. However, the associations with the PASAT were driven by the two strongest responders in growth factors who also had the strongest improvement in cognitive function and should thus be interpreted with caution.

Next, we aimed to determine whether levels of BDNF, PDGF-BB, and TGF $\beta 1$, which were induced by in vivo tes- 

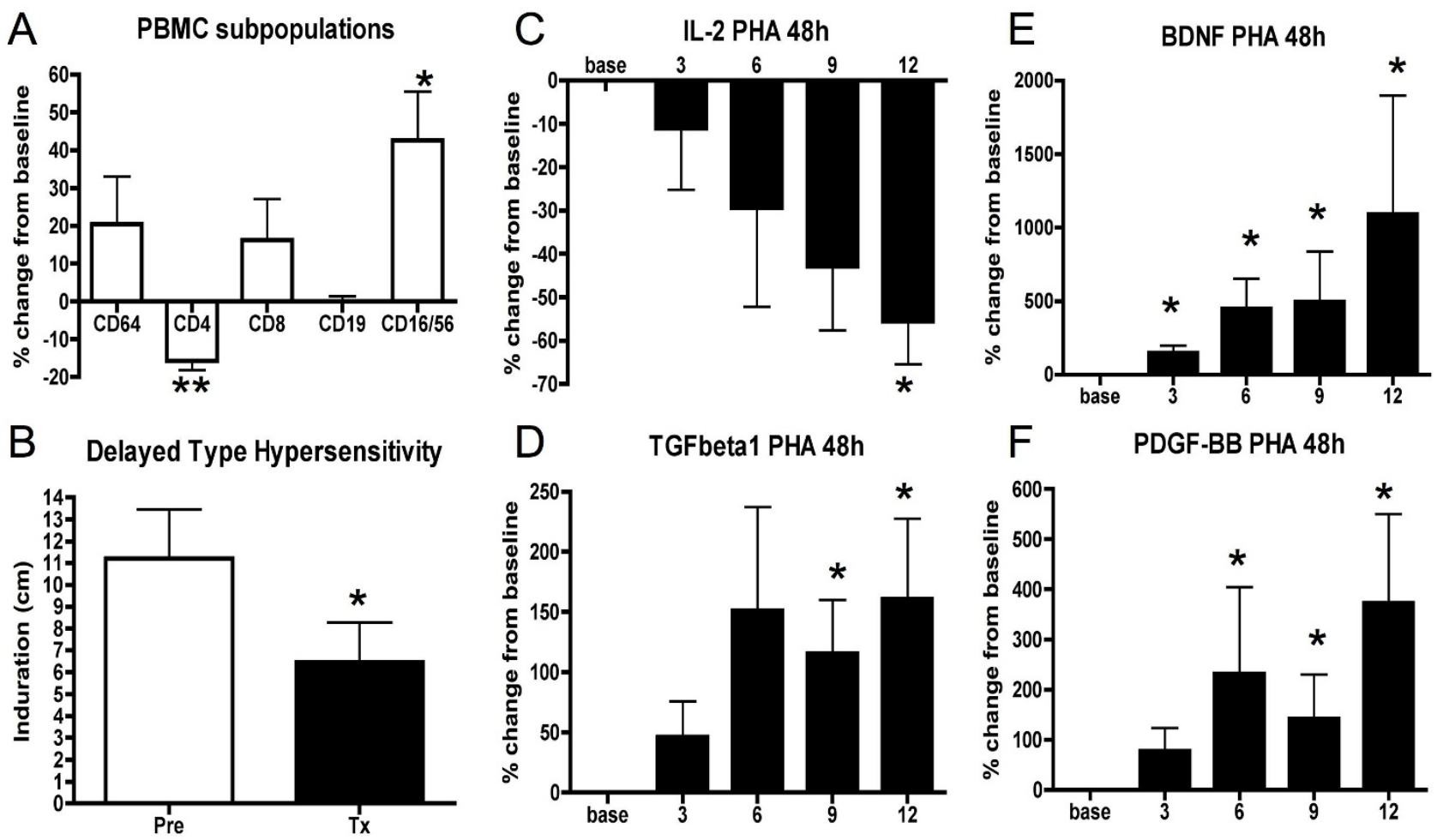

Figure I

Immunomodulation and growth factor induction by testosterone treatment in 10 male MS patients. A, Testosterone treatment significantly decreased CD4+ T cell and increased CD 16/56+ NK cell percentages. B, Treatment also significantly decreased delayed type hypersensitivity recall responses. C-F, In addition, treatment significantly decreased IL-2 and increased TGF $\beta$ I, BDNF and PDGF-BB levels produced by PHA stimulated peripheral blood mononuclear cells (PBMCs) during testosterone treatment (months 3-12) compared to baseline (base). Protein levels are expressed as the mean percent change compared with the mean from two pretreatment baseline time points. Mean month 12 concentrations were $670.5 \pm$ $223.4 \mathrm{pg} / \mathrm{ml}$ for IL-2, I552.0+273.3 pg/ml for TGF $\beta$ I, $246.1 \pm 40.37 \mathrm{pg} / \mathrm{ml}$ for BDNF and $42.6 \pm$ I5.6 pg/ml for PDGF-BB, respectively.

tosterone treatment, were functionally significant. Glutamate excitotoxicity is a widely used model for neurotoxicity and is thought to contribute to neurodegeneration observed in MS [23]. Thus, to test the biological significance of growth factor levels produced by immune cells during treatment, neuronal cultures were exposed to $2 \mathrm{~h}$ of $1 \mathrm{mM}$ glutamate in the presence or absence of recombinant growth factors similar to the levels seen in the best treatment responder at month $12(2000 \mathrm{pg} / \mathrm{ml}$ TGF $\beta 1,500$ pg/ml BDNF, 100 pg/ml PDGF-BB). Brightfield microscopy images indicated that addition of growth factors induced partial protection of axonal integrity in those cultures (black arrows) and decreased the number of TUNEL positive cells (white triangles, Figure 2A-C). $\mathrm{LDH}$ quantification showed that the addition of growth factors during glutamate exposure significantly reduced
LDH release from neuronal cultures, in line with a neuroprotective effect $(\mathrm{p}=.04$, Figure 2D).

\section{Discussion}

Our data suggest that testosterone treatment in MS is associated with effects on markers that could play a role in the inflammatory as well as the neurodegenerative component of the disease. A decrease in DTH responses, decreased IL- 2 and increased TGF $\beta 1$ production suggest an anti-inflammatory effect. This was accompanied by a decrease in CD4+ cells and an increase in NK cells. Based on our current understanding of MS pathogenesis, CD4+ autoreactive $\mathrm{T}$ cells and their differentiation into a Th1 phenotype are crucial events in disease development, and these cells are probably also important players in the longterm evolution of the disease [24], while NK cells have 



\section{Figure 2}

Growth factors reduce neurotoxicity in vitro. Neuroprotection against glutamate toxicity (I mM for $2 \mathrm{~h})$ by growth factors at concentrations similar to those at treatment month 12 in the clinical trial $(2000 \mathrm{pg} / \mathrm{ml}$ TGF $\beta$ I, $500 \mathrm{pg} / \mathrm{ml} \mathrm{BDNF}, \mathrm{I00} \mathrm{pg} /$ $\mathrm{ml}$ PDGF-BB). A-C, Brightfield microscopy images indicate that addition of growth factors during glutamate exposure induced partial protection of axonal integrity in those cultures (black arrows) and decreased the number of TUNEL positive cells (white triangles), representative images shown from 8 experiments. D, a protective effect was confirmed quantitatively by a significant reduction in LDH release. LDH data are shown from 8 independent experiments with wells run in duplicate for each condition.

been suggested to play a regulatory role by killing myelinspecific T cells and immature dendritic cells, promoting regulatory $\mathrm{T}$ cells and enhancing Th2-like responses [25].

Both IL-2 and TGF $\beta 1$ have been proposed as treatment targets in MS. Blocking the IL-2 $\alpha$ receptor chain with the monoclonal antibody daclizumab has been shown to decrease active lesions on MRI [26]. Interestingly, daclizumab treatment is also accompanied by a decrease in CD4+
$\mathrm{T}$ cells, as well as an increase in a subpopulation of NK cells numbers [27], consistent with our results on alterations in lymphocyte subpopulations during testosterone treatment.

The role of TGF $\beta 1$ in the immune system is complex as it can affect multiple cell lineages, either promoting or opposing their differentiation, survival, and proliferation. However, TGF $\beta 1$ appears to be a critical modulator of T 
cell-mediated self-reactivity [28] and has been successfully used to treat EAE [29]. Unfortunately, a clinical trial of TGFB2 administration in secondary-progressive MS had to be stopped due to nephrotoxicity of the recombinant cytokine [30].

In addition to these immunomodulatory effects, we saw significant increases in growth factor production by PBMCs. Neuroprotective effects of testosterone treatment have been described using both in vitro cultures and in vivo models. Since testosterone is lipophilic, in vivo effects of systemic testosterone treatment are thought to be mediated by testosterone crossing the blood brain barrier. In the CNS, testosterone may bind androgen receptors or may be converted by aromatase to estrogen, with estrogen known to have neuroprotective properties [31]. Here, we describe a novel potential neuroprotective pathway of testosterone treatment, namely through the induction of BDNF, PDGF-BB, and TGF $\beta 1$ by peripheral blood immune cells.

This is relevant to MS since neurotrophic factors such as BDNF have been detected in infiltrating immune cells in CNS lesions in both experimental autoimmune encephalomyelitis (EAE) [32] and MS [33] and it has been suggested that the immune cell-mediated import of BDNF and other neurotrophic factors into the central nervous system has the functional relevance of curbing the detrimental effects of inflammation on the surrounding tissue [19]. Supporting the clinical relevance of this phenomenon, an increase in BDNF production by PBMCs during relapse was previously only observed in patients who achieved full recovery, while patients with incomplete recovery demonstrated no alterations in BDNF production [34]. In addition, a recent study has shown correlations of BDNF production by peripheral immune cells with MRI-based measures of disease severity. Lower BDNF production was associated with lower Magnetic Transfer Ratio (MTR) in normal appearing white matter, suggesting more white matter damage in patients with lower BDNF production [35].

The neuroprotective effects in vivo and in vitro of BDNF are well known [36]. PDGF-BB has also been shown to be neuroprotective in vitro [37] and in vivo [38]. It is interesting to note that TGF $\beta 1$, in addition to its anti-inflammatory effects, also protected neurons from glutamate toxicity in vitro and in vivo [39]. Supporting the protective potential of growth factors produced by PBMCs in our study, we found that a combination of recombinant growth factors at similar concentrations as seen at month 12 of treatment could reduce glutamate-induced neurotoxicity in vitro. In this regard, it is intriguing that when the subjects in our study were assessed for MRI and clinical outcomes, a slowing in brain atrophy and an increase in cognitive function was observed during testosterone treatment as compared to baseline [20].

\section{Conclusion}

Previously, clinical trials using neurotrophic factors have been disappointing in neurodegenerative diseases despite promising results from pre-clinical studies [40]. The negative results of these clinical trials have highlighted that the manner and site of administration are of critical importance. Similarly, anti-inflammatory strategies in MS using monoclonal antibodies or recombinant cytokines have been associated with either partial efficacy or significant toxicities.

In contrast, treatment with physiological levels of testosterone is safe and appears to orchestrate simultaneous alterations in multiple growth factors and cytokines with the delivery system being the subjects' own peripheral blood immune cells. This immunomodulatory and potential neuroprotective pathway warrants further study in MS and other neurodegenerative diseases, which contain an inflammatory component, namely Alzheimer's Disease, Parkinson's disease and spinal cord injury [41].

\section{List of abbreviations}

BDNF: Brain-derived neurotrophic factor; CNTF: Ciliary neurotrophic factor; DTH: Delayed type hypersensitivity; EAE: Experimental autoimmune encephalomyelitis; EDSS: Expanded disability status scale; IL: Interleukin; LDH: Lactate Dehydrogenase; MRI: Magnetic resonance imaging; MS: Multiple sclerosis; NGF: Nerve growth factor; NK cell: Natural killer cell; NT-3: Neurotrophin 3; PASAT: Paced Auditory Serial Addition Task; PBMCs: Peripheral blood mononuclear cells; PDGF: Plateletderived growth factor; PHA: Phytohemagglutinin; RRMS: Relapsing-remitting MS; TGF: Transforming growth factor; TNF: Tumor necrosis factor.

\section{Competing interests}

The authors declare that they have no competing interests.

\section{Authors' contributions}

SMG contributed to study design and concept, acquired the immunological data, performed the neurotoxicity assay, and was responsible for analysis, interpretation and preparation of the manuscript. SC contributed to the neurotoxicity assay and critically revised the manuscript. BSG was responsible for patient assessment and acquisition of the clinical data and critically revised the manuscript. RRV obtained funding, was responsible for study design and concept and contributed to interpretation and preparation of the manuscript. All authors have read and approved the final manuscript. 


\section{Acknowledgements}

We would like to thank Dr Jeff Gornbein, Senior Statistician, Statistical and Biomedical Consulting Clinic, UCLA Dept of Biomathematics, for assisting with the statistical analyses. This study was supported by grants from the National Multiple Sclerosis Society (NMSS) (RG3239 and CA 1028) and the National Institutes of Health (NIH) (NS062II7) to R.R.V. Stefan M Gold is a NMSS post-doctoral fellow (FG I702-A-I).

\section{References}

I. McFarland HF, Martin R: Multiple sclerosis: a complicated picture of autoimmunity. Nat Immunol 2007, 8:9/3-9.

2. Hemmer B, Hartung HP: Toward the development of rational therapies in multiple sclerosis: what is on the horizon? Ann Neurol 2007, 62:3|4-26.

3. Bebo BF Jr, Zelinka-Vincent E, Adamus G, Amundson D, Vandenbark $A A$, Offner $H$ : Gonadal hormones influence the immune response to PLP |39-|5 | and the clinical course of relapsing experimental autoimmune encephalomyelitis. J Neuroimmunol 1998, 84: $122-130$

4. Smith ME, Eller NL, McFarland HF, Racke MK, Raine CS: Age dependence of clinical and pathological manifestations of autoimmune demyelination. Implications for multiple sclerosis. Am J Pathol 1999, I55: I |47-I I6I.

5. Ahmed SA, Penhale WJ: The influence of testosterone on the development of autoimmune thyroiditis in thymectomized and irradiated rats. Clin Exp Immunol 1982, 48:367-374.

6. Fitzpatrick F, Lepault F, Homo-Delarche F, Bach JF, Dardenne M: Influence of castration, alone or combined with thymectomy, on the development of diabetes in the nonobese diabetic mouse. Endocrinology 1991, I 29:1382-1390.

7. Fox HS: Androgen treatment prevents diabetes in nonobese diabetic mice. J Exp Med 1992, 175: I 409-14I2.

8. Harbuz MS, Perveen-Gill Z, Lightman SL, Jessop DS: A protective role for testosterone in adjuvant-induced arthritis. $\mathrm{Br} J \mathrm{Rheu}-$ matol 1995, 34: I I 17-II22.

9. Palaszynski KM, Loo KK, Ashouri JF, Liu HB, Voskuhl RR: Androgens are protective in experimental autoimmune encephalomyelitis: implications for multiple sclerosis. J Neuroimmunol 2004, I 46: | 44-52

10. D'Agostino P, Milano S, Barbera C, Di Bella G, La Rosa M, Ferlazzo V, Farruggio R, Miceli DM, Miele M, Castagnetta L, Cillari E: Sex hormones modulate inflammatory mediators produced by macrophages. Ann N Y Acad Sci 1999, 876:426-429.

11. Li ZG, Danis VA, Brooks PM: Effect of gonadal steroids on the production of IL-I and IL-6 by blood mononuclear cells in vitro. Clin Exp Rheumatol 1993, I I:157-162.

12. Liva SM, Voskuhl RR: Testosterone acts directly on CD4+ $\mathbf{T}$ lymphocytes to increase IL-10 production. J Immunol 200I, 167:2060-2067.

13. Gold SM, Voskuhl RR: Testosterone replacement therapy for the treatment of neurological and neuropsychiatric disorders. Curr Opin Investig Drugs 2006, 7:625-30.

14. Bialek M, Zaremba P, Borowicz KK, Czuczwar SJ: Neuroprotective role of testosterone in the nervous system. Pol J Pharmacol 2004, 56:509-518.

15. Ogata T, Nakamura Y, Tsuji K, Shibata T, Kataoka K: Steroid hormones protect spinal cord neurons from glutamate toxicity. Neuroscience 1993, 55:445-449.

16. Lustig RH: Sex hormone modulation of neural development in vitro. Horm Behav 1994, 28:383-395.

17. Kerschensteiner M, Gallmeier E, Behrens L, Leal VV, Misgeld T, Klinkert WE, Kolbeck R, Hoppe E, Oropeza-Wekerle RL, Bartke I, Stadelmann C, Lassmann H, Wekerle H, Hohlfeld R: Activated human T cells, $B$ cells and monocytes produce brain-derived neurotrophic factor (BDNF) in vitro and in brain lesions: a neuroprotective role of inflammation? J Exp Med 1999, 189:865-870

18. Hammarberg H, Lidman O, Lundberg C, Eltayeb SY, Gielen AW, Muhallab S, Svenningsson A, Lindå H, Meide PH van Der, Cullheim S, Olsson T, Piehl F: Neuroprotection by encephalomyelitis: rescue of mechanically injured neurons and neurotrophin production by CNS-infiltrating $T$ and natural killer cells. J Neurosci 2000, 20:5283-5291.
19. Hohlfeld R: Neurotrophic cross-talk between the nervous and immune systems: relevance for repair strategies in multiple sclerosis? J Neurol Sci 2008, 265:93-6.

20. Sicotte NL, Giesser BS, Tandon V, Klutch R, Steiner B, Drain AE, Shattuck DW, Hull L, Wang HJ, Elashoff RM, Swerdloff RS, Voskuhl RR: Testosterone treatment in multiple sclerosis: a pilot study. Arch Neurol 2007, 64:683-688.

21. Sicotte NL, Liva SM, Klutch R, Pfeiffer P, Bouvier S, Odesa S, Wu TC, Voskuhl RR: Treatment of multiple sclerosis with the pregnancy hormone estriol. Ann Neurol 2002, 52:42I-8.

22. Soldan SS, Alvarez Retuerto AI, Sicotte NL, Voskuhl RR: Immune modulation in multiple sclerosis patients treated with the pregnancy hormone estriol. J Immunol 2003, I 7 I:6267-74.

23. Gonsette RE: Oxidative stress and excitotoxicity: a therapeutic issue in multiple sclerosis? Mult Scler 2008, 14:22-34.

24. Sospedra M, Martin R: Immunology of multiple sclerosis. Annu Rev Immunol 2005, 23:683-747.

25. Morandi B, Bramanti P, Bonaccorsi I, Montalto E, Oliveri D, Pezzino G, Navarra M, Ferlazzo G: Role of natural killer cells in the pathogenesis and progression of multiple sclerosis. Pharmacol Res 2008, 57:I-5.

26. Bielekova B, Richert N, Howard T, Blevins G, Markovic-Plese S, McCartin J, Frank JA, Würfel J, Ohayon J, Waldmann TA, McFarland HF, Martin R: Humanized anti-CD25 (daclizumab) inhibits disease activity in multiple sclerosis patients failing to respond to interferon beta. Proc Natl Acad Sci USA 2004, I 0 I :8705-8708.

27. Bielekova B, Catalfamo M, Reichert-Scrivner S, Packer A, Cerna M, Waldmann TA, McFarland H, Henkart PA, Martin R: Regulatory CD56(bright) natural killer cells mediate immunomodulatory effects of IL-2Ralpha-targeted therapy (daclizumab) in multiple sclerosis. Proc Natl Acad Sci USA 2006, I03:594I-6.

28. Rubtsov YP, Rudensky AY: TGF $\beta$ signalling in control of T-cellmediated self-reactivity. Nat Rev Immunol 2007, 7:443-453.

29. Racke MK, Dhib-Jalbut S, Cannella B, Albert PS, Raine CS, McFarlin $D E$ : Prevention and treatment of chronic relapsing experimental allergic encephalomyelitis by transforming growth factor-beta I. J Immunol I99I, I46:3012-30I7.

30. Calabresi PA, Fields NS, Maloni HW, Hanham A, Carlino J, Moore J, Levin MC, Dhib-Jalbut S, Tranquill LR, Austin H, McFarland HF, Racke MK: Phase I trial of transforming growth factor beta 2 in chronic progressive MS. Neurology 1998, 5 I:289-292.

31. Brann DW, Dhandapani K, Wakade C, Mahesh VB, Khan MM: Neurotrophic and neuroprotective actions of estrogen: basic mechanisms and clinical implications. Steroids 2007, 72:38I-405.

32. Muhallab S, Lundberg C, Gielen AW, Lidman O, Svenningsson A, Piehl $F$, Olsson T: Differential expression of neurotrophic factors and inflammatory cytokines by myelin basic protein-specific and other recruited $T$ cells infiltrating the central nervous system during experimental autoimmune encephalomyelitis. Scand J Immunol 2002, 55:264-273.

33. Stadelmann C, Kerschensteiner M, Misgeld T, Brück W, Hohlfeld R, Lassmann $\mathrm{H}$ : BDNF and gp/45trkB in multiple sclerosis brain lesions: neuroprotective interactions between immune and neuronal cells? Brain 2002, I 25:75-85.

34. Caggiula M, Batocchi AP, Frisullo G, Angelucci F, Patanella AK, Sancricca C, Nociti V, Tonali PA, Mirabella M: Neurotrophic factors and clinical recovery in relapsing-remitting multiple sclerosis. Scand J Immunol 2005, 62:176-82.

35. Weinstock-Guttman B, Zivadinov R, Tamaño-Blanco M, Abdelrahman N, Badgett D, Durfee J, Hussein S, Feichter J, Patrick K, Benedict R, Ramanathan M: Immune cell BDNF secretion is associated with white matter volume in multiple sclerosis. J Neuroimmunol 2007, 188:167-74.

36. Lykissas MG, Batistatou AK, Charalabopoulos KA, Beris AE: The role of neurotrophins in axonal growth, guidance, and regeneration. Curr Neurovasc Res 2007, 4: I43-5I.

37. Tseng HC, Dichter MA: Platelet-derived growth factor-BB pretreatment attenuates excitotoxic death in cultured hippocampal neurons. Neurobiol Dis 2005, 19:77-83.

38. Kawabe T, Wen TC, Matsuda S, Ishihara K, Otsuda H, Sakanaka M: Platelet-derived growth factor prevents ischemia-induced neuronal injuries in vivo. Neurosci Res 1997, 29:335-43.

39. Henrich-Noack P, Prehn JH, Krieglstein J: Neuroprotective effects of TGF-beta I. J Neural Transm Suppl 1994, 43:33-45. 
40. Thoenen $H$, Sendtner $M$ : Neurotrophins: from enthusiastic expectations through sobering experiences to rational therapeutic approaches. Nat Neurosci 2002:1046-50.

41. Esiri MM: The interplay between inflammation and neurodegeneration in CNS disease. J Neuroimmunol 2007, 184:4-16.

Publish with Bio Med Central and every scientist can read your work free of charge

"BioMed Central will be the most significant development for disseminating the results of biomedical research in our lifetime. " Sir Paul Nurse, Cancer Research UK

Your research papers will be:

- available free of charge to the entire biomedical community

- peer reviewed and published immediately upon acceptance

- cited in PubMed and archived on PubMed Central

- yours - you keep the copyright

Submit your manuscript here:

http://www.biomedcentral.com/info/publishing_adv.asp 